\title{
Preventing neonatal herpes infections through maternal immunization
}

\author{
Yike Jiang ${ }^{1} \&$ David Leib ${ }^{*}, 1$ \\ ${ }^{1}$ Department of Microbiology \& Immunology, Geisel School of Medicine at Dartmouth, Lebanon, NH 03756, USA \\ * Author for correspondence: david.a.leib@dartmouth.edu
}

\begin{abstract}
"Compared with the long-term protection required of vaccines against genital HSV, maternal vaccines would only need to induce an antibody response during the perinatal period to be effective in the newbornCompared with the long-term protection required of vaccines against genital HSV, maternal vaccines would only need to induce an antibody response during the perinatal period to be effective in the newbor"
\end{abstract}

First draft submitted: 1 September 2017; Accepted for publication: 7 September 2017; Published online: 27 November 2017

Keywords: congenital infection • maternal immunization • neonatal HSV • vaccine

Pathogens that infect the fetus and newborn are known collectively by the acronym TORCH: Toxoplasma gondii, other, rubella virus, cytomegalovirus and herpes simplex virus (HSV). 'Other' pathogens include syphilis, varicellazoster virus, parvovirus B19, HIV and the most recent addition, Zika virus. These infections are a significant cause of mortality and morbidity, manifesting with neurological sequelae in the survivors. Sensorineural deafness, seizures, microcephaly and intellectual disability are some of the neurological outcomes common to many of these congenital infections [1]. For HSV, neurological infection is present in about a third of neonatal HSV infections. Even with antiviral therapy, there is still a high likelihood of permanent neurological abnormalities [2]. Here we present evidence that maternal immunization to induce virus-specific antibodies would be an effective strategy to prevent neonatal HSV.

The global incidence of neonatal HSV is estimated to be 1.03 per 10,000 live births annually [3]. However, estimates of neonatal HSV have been reported to be as high as 1 in 3200 live births in the USA [4]. Globally, HSV-2 causes approximately $70 \%$ of neonatal HSV, but HSV-1 is thought to be the major cause in the Americas, Europe and Western Pacific [3]. Acquisition occurs perinatally when the neonate is exposed to vaginal HSV during parturition. When active maternal lesions prompt a cesarean delivery, HSV transmission is prevented, but HSV shedding is often asymptomatic and prophylaxis is often unexploited [4]. Therefore, new prophylactic avenues are being explored to prevent the global burden of this disease.

The idea that maternal antibodies can protect neonates from HSV originated from clinical observations [4,2]. Fifty percent of babies delivered to women with first-episode primary infection develop neonatal HSV disease while only $1-2 \%$ of babies delivered to women with recurrent HSV develop the disease [4,5]. The most likely explanation for this observation is that antiviral maternal antibodies induced during previous infection transfer to the neonate and protect them from HSV disease [6]. This idea was further supported by animal studies in the 1980s demonstrating that prior to maternal infection and maternal neutralizing, antibody titers correlate with protection in pups $[7,8]$. Despite these clinical and animal studies, there has been surprisingly little effort to translate these findings to the clinic. While the development of acyclovir in the 1980s reduced the urgency for development of immune-based approaches, treatment with intravenous acyclovir for neonatal herpes has limitations. A high-degree of clinical suspicion and empirical therapy are critical for successful acyclovir treatment. This is challenging since neonatal HSV symptoms are nonspecific and accurate, and timely diagnosis is often hampered due to initial suspicion of bacterial sepsis [9]. Moreover, even when high-dose acyclovir is given, the risk of neurological sequelae remains high [10]. We believe that these shortcomings may be overcome by strategies to stimulate maternal antibody production during pregnancy. In a recent study by our group, we found that antiviral maternal antibodies transfer efficiently to the naive neural tissue of newborn mice prior to infection and effectively prevent neurological HSV

Future $\because \%$ Medicine 
infection [11]. We also uncovered evidence that these maternal antibodies persist in the neural tissues of neonates in humans. This work therefore documents a neuroprotective role of maternal antibodies and underscores the potential of maternal immunization to prevent congenital neurological infections.

Despite the multiple failures in the HSV vaccine field, we propose that maternal vaccination aimed at preventing neonatal herpes is feasible. To date, all vaccine clinical trials for genital HSV have been discontinued due to low efficacy in horizontal (adult-to-adult) transmission. The bar for success of these vaccines is high: they are required to induce a combined cell-mediated and humoral immune response that prevents HSV shedding for the entire sexually active phase of the recipient. While the development of vaccines to prevent the morbidity of adult genital herpes is important, the predominant situation in which genital herpes leads to mortality is when HSV is transmitted to neonates. Therefore, specific immunization strategies to prevent neonatal HSV warrant independent consideration. Compared with the adult genital herpes vaccines, we hypothesize that a successful maternal vaccine would only need to clear a relatively low immunological bar. It would only need to induce a robust humoral response during the perinatal period when HSV transmission occurs. Given that primary maternal infection leads to the greatest risk of transmission, the target population of this vaccine would be the most at-risk women who are seronegative for HSV-1 and HSV-2. This maternal vaccine would need to: induce a robust anti-HSV IgG response against HSV-1 and HSV-2; cross the placenta to the fetus; persist in the neonate during the perinatal period; and ultimately, protect the neonate from HSV disease and sequelae. Since naturally occurring maternal IgG readily crosses the placenta and persists in the newborn for up to 6 months [12], the induction of maternal antibodies is an ideal strategy for preventing such perinatal infections.

There are several existing genital HSV vaccines that induce a robust humoral response. The Chiron subunit vaccine induced neutralizing antibodies against $\mathrm{gD}$ and $\mathrm{gB}$ that were greater than or equivalent to naturally acquired infections $[13,14]$. Newer vaccines in current pipelines, including replication-defective vectors $[15,16]$ and trivalent subunit vaccines [17], can all potently induce protective antibodies in animal models. Additionally, most adult humans are infected with HSV-1 and HSV-2, so purifying hyperimmune antibodies from pooled human sera for passive immunization would also be a feasible alternative. At last, these IgGs could be engineered for specific epitope recognition, specific FcR binding, or greater half-life stability through in vitro methods. It remains to be tested whether antibodies from these strategies could transfer, persist and protect the newborn from HSV infection.

In addition to testing the efficacy of these maternal vaccines, there are still many outstanding questions that remain to be addressed. Which antibodies, in terms of subclass and antigen specificity, are most protective against neonatal HSV? How do these antibodies exert antiviral function? Do antibodies in milk also play a role in preventing neonatal HSV disease? And at last, how do these antibodies gain access to and persist in naive neural tissue? Recent studies show that maternal antibodies can transfer into the developing peripheral and central nervous system during gestation $[11,18]$. These findings coupled with reports that maternal antibodies are effective against congenital Zika [19] and cytomegalovirus [20] infections suggest a broader applicability of maternal immunizations to other TORCH pathogens.

In summary, the efficacy of maternal vaccines against neonatal HSV has been predicted by studies as early as the 1980s. Compared with the long-term protection required of vaccines against genital HSV, maternal vaccines would only need to induce an antibody response during the perinatal period to be effective in the newborn. Whether a vaccination strategy would supersede or synergize with acyclovir treatment remains an open question, but the newly-discovered ability of maternal antibodies to protect the newborn nervous system provides compelling impetus for this approach. Development of maternal immunizations against neonatal HSV is highly warranted for preventing this global disease.

\section{Financial \& competing interests disclosure}

The authors appreciate input from Audra Charron and other Leib Lab members, support from the Munck-Pfefferkorn Education and Research Fund to DA Leib, and RO1 EY09083 and PO1 Al098681 to DA Leib. Y Jiang received support from Geisel School of Medicine Molecular and Cellular Biology Program Training Grant T32GM8704 and NRSA Individual Predoctoral Fellowship F30EY026487 from the NIH. The authors have no other relevant affiliations or financial involvement with any organization or entity with a financial interest in or financial conflict with the subject matter or materials discussed in the manuscript apart from those disclosed.

No writing assistance was utilized in the production of this manuscript. 


\section{References}

1 Coyne CB, Lazear HM. Zika virus - reigniting the TORCH. Nat. Rev. Microbiol. 14(11), 707-715 (2016).

2 Corey L, Wald A. Maternal and neonatal herpes simplex virus infections. N. Engl. J. Med. 361(14), 1376-1385 (2009).

3 Looker KJ, Magaret AS, May MT et al. First estimates of the global and regional incidence of neonatal herpes infection. Lancet Glob. Health 5(3), e300-e309 (2017).

4 Brown ZA, Wald A, Morrow RA, Selke S, Zeh J, Corey L. Effect of serologic status and cesarean delivery on transmission rates of herpes simplex virus from mother to infant. JAMA 289(2), 203 (2003).

5 Prober CG, Sollender WM, Yasukawa LL et al. Low risk of herpes simplex virus infections in neonates exposed to the virus at the time of vaginal delivery to mothers with recurrent genital herpes simplex virus infections. N. Engl. J. Med. 316(5), 240-244 (1987).

6 Ashley RL, Dalessio J, Burchett $S$ et al. Herpes simplex virus-2 (HSV-2) type-specific antibody correlates of protection in infants exposed to HSV-2 at birth. J. Clin. Invest. 90(2), 511-514 (1992).

7 Kohl S, Loo LS. The relative role of transplacental and milk immune transfer in protection against lethal neonatal herpes simplex virus infection in mice. J. Infect. Dis. 149(1), 38-42 (1984).

8 Hayashi Y, Wada T, Mori R. Protection of newborn mice against herpes simplex virus infection by prenatal and postnatal transmission of antibody. J. Gen. Virol. 64(5), 1007-1012 (1983).

9 Demmler-Harrison GJ. Neonatal herpes simplex virus infection: clinical features and diagnosis. UpToDate (2016). www.uptodate.com/contents/neonatal-herpes-simplex-virus-infection-clinical-features-and-diagnosis?source=search_result\&search= neonatalhsv\&selectedTitle=1 60\# H1

10 Kimberlin DW, Lin CY, Jacobs RF et al. Safety and efficacy of high-dose intravenous acyclovir in the management of neonatal herpes simplex virus infections. Pediatrics 108(2), 230-238 (2001).

11 Jiang Y, Patel CD, Manivanh R et al. Maternal antiviral immunoglobulin accumulates in neural tissue of neonates to prevent HSV neurological disease. MBio 8(4), e00678-e00717 (2017).

12 Niewiesk S. Maternal antibodies: clinical significance, mechanism of interference with immune responses and possible vaccination strategies. Front. Immunol. 5, 446 (2014).

13 Langenberg AG, Burke RL, Adair SF et al. A recombinant glycoprotein vaccine for herpes simplex virus type 2: safety and immunogenicity [corrected]. Ann. Intern. Med. 122(12), 889-898 (1995).

14 Corey L, Langenberg AG, Ashley R et al. Recombinant glycoprotein vaccine for the prevention of genital HSV-2 infection: two randomized controlled trials. Chiron HSV Vaccine Study Group. JAMA 282(4), 331-340 (1999).

15 Hoshino Y, Dalai SK, Wang K et al. Comparative efficacy and immunogenicity of replication-defective, recombinant glycoprotein and DNA vaccines for herpes simplex virus 2 infections in mice and guinea pigs. J. Virol. 79(1), 410-418 (2005).

16 Halford WP, Püschel R, Gershburg E, Wilber A, Gershburg S, Rakowski B. A live-attenuated HSV-2 ICP0-virus elicits 10- to 100-times greater protection against genital herpes than a glycoprotein D subunit vaccine. PLoS ONE 6(3), e17748 (2011).

17 Awasthi S, Hook LM, Shaw CE et al. An HSV-2 trivalent vaccine is immunogenic in rhesus macaques and highly efficacious in guinea pigs. PLOS Pathog. 13(1), e1006141 (2017).

18 Kowal C, Athanassiou A, Chen H, Diamond B. Maternal antibodies and developing blood-brain barrier. Immunol. Res. 63(1-3), 18-25 (2015).

19 Sapparapu G, Fernandez E, Kose $\mathrm{N}$ et al. Neutralizing human antibodies prevent Zika virus replication and fetal disease in mice. Nature 540(7633), 443-447 (2016).

20 Nelson CS, Cruz DV, Tran D et al. Preexisting antibodies can protect against congenital cytomegalovirus infection in monkeys. JCI Insight doi:10.1172/jci.insight.94002 (2017) (Epub ahead of print). 